\title{
Pengaruh Program Pengembangan Usaha Agribisnis Perdesaan (PUAP) terhadap Produksi dan Pendapatan Petani Padi \\ (Studi Kasus : Gapoktan Belega Mandiri di Desa Belega, Kecamatan Blahbatuh, Kabupaten Gianyar)
}

NI PUTU RISKIANA ULANDARI, MADE ANTARA, A.A. AYU WULANDIRA SAWITRI DJELANTIK

\author{
Program Studi Agribisnis, Fakultas Pertanian, Universitas Udayana \\ Jl. PB. Sudirman Denpasar 80323 \\ Email: riskianaulandari@yahoo.com \\ antara_unud@yahoo.com
}

\author{
Abstract \\ The Effect of Pengembangan Usaha Agribisnis Perdesaan (PUAP) \\ Program on the Rice Farmers' Production and Income \\ (Case Study: Gapoktan of Belega Mandiri in Belega Village, \\ Blahbatuh Sub-District, Gianyar Regency)
}

Pengembangan Usaha Agribisnis Perdesaan (PUAP) Program is a form of facilitation of business capital assistance for member farmers, either farmers, peasants, farm workers and farm households coordinated by the Gabungan Kelompok Tani (Gapoktan). This research was conducted to investigate the effect of PUAP program on the production and income of rice farmers in the Joint Farmer Group of Belega Mandiri. The analytical method used to investigate the effect of PUAP on production was multiple linear regression analysis with Cobb-Douglas production function model in the form of natural logarithm, while to analyze the effect of PUAP on income was done by comparative analysis on cost, revenue, income, and total of R/C. The findings showed that PUAP has a significant effect on rice production in the Joint Farmer Group of Belega Mandiri. In addition to PUAP, factors affecting rice production include seeds and labors. The average cost, revenue, and income of PUAP users per hectare was higher than those of non-PUAP users. The t-test results showed that the average total of R/C value between the PUAP users and non-PUAP users was significantly different. This indicates that farming of PUAP users were more efficient than those of non-PUAP users.

Keywords: PUAP program, dummy variable, rice farming, production, and income

\section{Pendahuluan}

\subsection{Latar Belakang}

Pertanian adalah ibu dari segala budaya. Pertanian berjalan dengan baik, maka budaya-budaya lainnya akan tumbuh dengan baik pula, tetapi manakala sektor ini diterlantarkan, maka semua budaya lainnya akan hancur, baik di darat dan di lautan (Xenophon dalam Daryanto, 2010). Sejalan dengan Program Pembangunan 
Pertanian yang berkaitan erat dengan pembangunan perdesaan dan peningkatan kesejahteraan masyarakat, terutama yang bergerak pada sektor pertanian, maka pemerintah mencanangkan Program Pengembangan Usaha Agribisnis Perdesaan (PUAP). PUAP merupakan bentuk fasilitasi bantuan modal usaha bagi petani anggota, baik petani pemilik, petani penggarap, buruh tani maupun rumah tangga tani yang dikoordinasikan oleh Gabungan Kelompok Tani atau Gapoktan (Permentan, 2015).

Provinsi Bali merupakan salah satu Provinsi penerima dana PUAP. Berdasarkan data pada Badan Pusat Statistik (2013), Kabupaten Tabanan dan Kabupaten Gianyar merupakan kebupaten dengan jumlah produksi padi tertinggi di Provinsi Bali. Berdasarkan data jumlah rumah tangga usaha pertanian yang menggunakan lahan sawah dari tahun 2003 sampai dengan tahun 2013, Kabupaten Gianyar mengalami penurunan lebih besar dibandingkan Kabupaten Tabanan (BPS, 2013). Hal inilah yang menarik perhatian peneliti untuk melakukan penelitian di Kabupaten Gianyar tepatnya di Kecamatan Blahbatuh. Jumlah produksi padi di Kabupaten Gianyar pada tahun 2015 adalah sejumlah 192.518 ton dan Kecamatan Blahbatuh dikategorikan sebagai salah satu Kecamatan dengan produksi padi tertinggi setelah Kecamatan Gianyar (BPS, 2015). Berdasarkan data pada BPTP Bali (2015) ada sembilan Gapoktan penerima dana PUAP di Kecamatan Blahbatuh, salah satu diantaranya yaitu Gapoktan Belega Mandiri. Gapoktan Belega Mandiri memiliki potensi lahan yang paling baik dibandingkan sembilan Gapoktan lain di Kecamatan Blahbatuh. Pengaruh program PUAP tidak selalu meningkatkan produksi dan pendapatan usahatani padi. Pengaruh program PUAP bergantung pada penggunaan dana yang dilakukan petani untuk usahatani padi serta faktor-faktor lain yang dapat mempengaruhi produksi dan pendapatan petani padi.

\subsection{Tujuan Penelitian}

Tujuan yang ingin dicapai dalam penelitian ini adalah untuk mengetahui (1) pengaruh program PUAP terhadap produksi usahatani padi di Gapoktan Belega Mandiri dan (2) pengaruh program PUAP terhadap tingkat pendapatan petani padi yang menggunakan PUAP, dibandingkan dengan petani yang tidak menggunakan PUAP di Gapoktan Belega Mandiri.

\section{Metode Penelitian}

\subsection{Lokasi dan Waktu Penelitian}

Pemilihan lokasi dilakukan secara sengaja (purposive) dengan alasan Gapoktan Belega Mandiri telah menerima dana PUAP sejak tahun 2009, pernah meraih juara dua dalam lomba subak se-Kabupaten Gianyar, dan sejak tahun 2012 hingga saat ini dipilih sebagai lokasi pelaksanaan sistem tanam padi jajar legowo oleh pemerintah. Pengambilan data dilakukan bulan Maret - April 2017. 


\subsection{Data dan Metode Pengumpulan Data}

Jenis data yang digunakan dalam penelitian ini adalah data kualitatif dan data kuantitatif. Ada dua sumber data dalam penelitian ini yakni data primer dan data sekunder. Metode yang digunakan untuk memperoleh data penelitian ini antara lain (1) wawancara langsung, (2) observasi, dan (3) studi dokumentasi.

\subsection{Populasi dan Sampel}

Populasi dalam penelitian ini adalah para petani padi yang bergabung dalam Gapoktan Belega Mandiri sejumlah 223 orang. Responden penelitian diambil sebanyak 33 orang pengguna PUAP secara sensus, selanjutnya untuk menyamakan proporsi responden yang menggunakan PUAP dengan yang tidak menggunakan PUAP, maka jumlah responden yang tidak menggunakan PUAP diambil sebanyak 33 orang secara acak, sehingga jumlah responden keseluruhan adalah 66 orang petani.

\subsection{Metode Analisis Data}

\subsubsection{Analisis faktor-faktor yang mempengaruhi produksi}

Fungsi Produksi Cobb Douglas digunakan untuk menganalisis pengaruh program PUAP terhadap produksi usahatani padi di Gapoktan Belega Mandiri. Menurut Soekartawi (2002) secara matematis fungsi produksi Cobb Douglas dapat ditulis sebagai berikut.

$$
\mathrm{Y}=\mathrm{aX} \mathrm{X}_{1}^{\mathrm{b} 1} \mathrm{X}_{2}^{\mathrm{b} 2} \ldots \mathrm{X}_{\mathrm{i}}^{\mathrm{bi}} \mathrm{e}^{\mathrm{u}}
$$

Persamaan tersebut dirubah ke dalam bentuk linier dengan cara melogaritmakan persamaan sehingga, menjadi :

$$
L n Y=b_{0}+b_{1} \operatorname{Ln} \mathrm{X}_{1}+b_{2} \operatorname{Ln} \mathrm{X}_{2}+b_{3} \operatorname{Ln} \mathrm{X}_{3}+b_{4} \operatorname{Ln} \mathrm{X}_{4}+b_{5} \operatorname{Ln} \mathrm{X}_{5}+\mathrm{c}_{\mathrm{i}} \operatorname{Ln} \mathrm{D}_{\mathrm{i}}
$$

Adapun pengujian hipotesis yang akan dilakukan adalah sebagai berikut.

a. Pengujian terhadap model penduga

Uji statistik yang digunakan untuk pengujian terhadap model penduga adalah uji F (Tenaya, 2009), yaitu:

$$
\mathrm{F}_{\text {hitung }}=\frac{\mathrm{R}^{2} /(\mathrm{k}-1)}{\left(1-\mathrm{R}^{2}\right) /(\mathrm{n}-\mathrm{k})}
$$

$\mathrm{F}$-tabel $=\mathrm{F}_{\alpha(\mathrm{k}-1, \mathrm{n}-\mathrm{k})}$

Keterangan :

$\mathrm{R}^{2}=$ Koefisien determinasi

$\mathrm{k}=$ Jumlah variabel termasuk intersep

$\mathrm{n}$ = Jumlah pengamatan 


\section{Kriteria Uji :}

$\mid$ F-hitung $\mid>\mathrm{F} \alpha(\mathrm{k}-1, \mathrm{n}-\mathrm{k})$, maka tolak $\mathrm{H}_{0}$

$\mid \mathrm{F}$-hitung $\mid<\mathrm{F} \alpha(\mathrm{k}-1, \mathrm{n}-\mathrm{k})$, maka terima $\mathrm{H}_{0}$

\section{b. Pengujian untuk masing-masing parameter}

Menurut Tenaya (2009) tujuan dilakukan uji-t adalah untuk menguji pengaruh masing-masing variabel $\mathrm{X}$ secara terpisah terhadap variabel $\mathrm{Y}$, yaitu dengan rumus:

$$
t_{\text {hitung }}=\frac{b_{i}}{s_{b i}}
$$

Dimana :

$\mathrm{S}_{\mathrm{bi}}=$ salah baku $\mathrm{b}_{\mathrm{i}}$

Kriteria uji :

$\mid \mathrm{t}$-hitung $\mid>\mathrm{t} \alpha / 2(\mathrm{n}-\mathrm{k})$, maka tolak $\mathrm{H}_{0}$

$\mid \mathrm{t}$-hitung $\mid<\mathrm{t} \alpha / 2(\mathrm{n}-\mathrm{k})$, maka terima $\mathrm{H}_{0}$

Metode penduga yang digunakan adalah metode kuadrat terkecil atau Ordinary Least Square (OLS). Kelayakan model diuji berdasarkan asumsi OLS yaitu multikolinearitas, homoskedastisitas dan normalitas error.

Pengaruh program PUAP terhadap produksi usahatani padi akan dijelaskan oleh koefisien variabel dummy dalam fungsi produksi (Nursyamsiah, 2010). Apabila $\mathrm{c}=$ koefisien variabel dummy nilainya siginifikan berarti variabel dummy berpengaruh nyata terhadap produksi usahatani padi atau ada perbedaan produksi antara petani pengguna PUAP $\left(\mathrm{D}_{1}\right)$ dengan petani bukan pengguna $\mathrm{PUAP}\left(\mathrm{D}_{0}\right)$.

\subsubsection{Uji-t tidak berpasangan (independent sample t-test)}

Independent sample t-test adalah uji statistika yang bertujuan untuk mengetahui perbedaan rata-rata dua kelompok data yang tidak saling berpasangan atau tidak saling berkaitan.Uji-t tidak berpasangan dilakukan dengan program aplikasi SPSS. Nilai signifikansi lebih kecil dari 0,05 ( $\mathrm{p}<0,05)$ berarti nilai-t hitung signifikan, yang berarti kedua kelompok berbeda secara nyata.

Uji-t independen ini memiliki asumsi/syarat yang mesti dipenuhi, yaitu (1) Datanya berdistribusi normal, (2) Kedua kelompok data independen (bebas), (3) Variabel yang dihubungkan berbentuk numerik dan kategorik (dengan hanya 2 kelompok).

\subsubsection{Analisis pendapatan usahatani dan $R / C$}

Menurut Soekartawi (2005) total pendapatan diperoleh dari total penerimaan dikurangi dengan total biaya dalam suatu proses produksi, sedangkan total penerimaan diperoleh dari produksi fisik dikalikan dengan harga produksi. Tingkat pendapatan usahatani dapat dinyatakan dalam persamaan matematika sebagai berikut 


$$
\begin{gathered}
\mathrm{I}_{\text {tunai }}=\mathrm{NP}-\mathrm{BT} \ldots \ldots \ldots \\
\mathrm{I}_{\text {total }}=\mathrm{NP}-(\mathrm{BT}+\mathrm{BD})
\end{gathered}
$$

Keterangan :

$\mathrm{I}_{\mathrm{tunai}}=$ Tingkat pendapatan bersih tunai

$\mathrm{I}_{\text {total }}=$ Tingkat pendapatan bersih total

$\mathrm{NP}=$ Nilai produk, merupakan hasil perkalian jumlah output dengan harga

$\mathrm{BT}=$ Biaya tunai

$\mathrm{BD}=$ Biaya diperhitungkan

Perhitungan $R / C$ dapat dirumuskan sebagai berikut :

$$
\begin{gathered}
R / C \text { atas biaya tunai }=\frac{\text { Total Penerimaan }}{\text { Total Biaya Tunai }}=\frac{Y . P y}{\mathrm{BT}} . \\
R / C \text { atas biaya total }=\frac{\text { Total Penerimaan }}{\text { Total Biaya Tunai }}=\frac{\mathrm{Y} \cdot \mathrm{Py}}{\mathrm{BT}+\mathrm{BD}} .
\end{gathered}
$$

Keterangan:

$\mathrm{Y} \quad=$ Total produksi

Py $\quad=$ Harga produk

BT = Biaya tunai

BD = Biaya diperhitungkan

Pengaruh program PUAP terhadap pendapatan akan diketahui dari nilai $p$ value $\mathrm{R} / \mathrm{C}$ total setelah dilakukan uji t-tidak berpasangan pada nilai $\mathrm{R} / \mathrm{C}$ total antara petani pengguna dan bukan pengguna PUAP. Nilai $p$-value $\mathrm{R} / \mathrm{C}$ total berbeda secara nyata ( $p$-value $<0,05$ ) berarti, adanya program PUAP berpengaruh terhadap pendapatan petani padi di Gapoktan Belega Mandiri.

\section{Hasil dan Pembahasan}

\subsection{Hasil Analisis Pengaruh Program PUAP terhadap Produksi Usahatani Padi di Gapoktan Belega Mandiri}

\subsubsection{Penggunaan input pada usahatani padi}

Pada umumnya input yang digunakan terdiri dari lahan, benih, pupuk urea, Pupuk Phonska, pupuk organik, obat-obatan, tenaga kerja, dan peralatan. Hasil uji statistik menunjukkan bahwa $p$-value luas lahan, benih, pupuk urea, dan pupuk organik lebih kecil dari derajat kesalahan atau $\alpha(0,05)$, sehingga dapat disimpulkan bahwa rata-rata luas lahan, benih, dan pupuk organik yang digunakan oleh petani pengguna PUAP dan bukan pengguna PUAP berbeda nyata. Pengguna PUAP dan bukan pengguna PUAP memiliki perbedaan dalam hal pemanfaatan luas tanam, benih, pupuk urea, dan pupuk organik. Nilai p-value Pupuk Phonska, obat-obatan, dan tenaga kerja lebih besar dari $\alpha(0,05)$. Nilai $p$-value mengindikasikan bahwa ratarata penggunaan pupuk urea, Phonska, obat-obatan, dan tenaga kerja antara petani pengguna dan bukan pengguna PUAP adalah sama. 


\subsubsection{Model fungsi produksi usahatani padi}

\subsubsection{Spesifikasi model}

Model spesifik fungsi produksi Cobb-Douglas dituliskan sebagai berikut.

$\ln Y=b o+b_{1} \ln X_{1}+b_{2} \ln X_{2}+b_{3} \ln X_{3}+b_{4} \ln X_{4}+b_{5} \ln X_{5}+b_{6} \ln X_{6}+c_{1} \ln D_{1}+e$

Keterangan :Y (produksi padi), $\mathrm{X}_{1}$ (luas lahan), $\mathrm{X}_{2}$ (benih), $\mathrm{X}_{3}$ (pupuk urea), $\mathrm{X}_{4}$ (pupuk phonska), $X_{5}$ (pupuk organik), $X_{6}$ (pestisida), $X_{7}$ (tenaga kerja), $\mathrm{D}_{1}$ (Dummy PUAP : 0 = bukan penguna PUAP dan $1=$ pengguna PUAP), e (residual).

Berdasarkan hasil analisis, maka diperoleh persamaan model fungsi produksi usahatani padi petani responden sebagai berikut :

$$
\begin{aligned}
\ln Y= & 3,997+1,003 \ln X_{1}+0,019 \ln X_{2}-0,003 \ln X_{3}-0,012 \ln X_{4}+0,002 \ln X_{5}- \\
& 0,001 \ln X_{6}-0,025 \ln X_{7}+0,104 \ln D_{1}
\end{aligned}
$$

Model persamaan regresi linear berganda yang diperoleh ternyata menyimpang dari uji asumsi klasik yaitu uji multikolinieritas. Hal ini ditunjukkan dengan adanya variabel independen pada model yang memiliki nilai VIF > 10 .

\subsubsection{Estimasi model fungsi produksi}

Menurut Kurniawan dan Yuniarto (2016) salah satu cara untuk mengatasi multikolinieritas adalah dengan mengganti atau mengeluarkan variabel yang mempunyai korelasi yang tinggi. Variabel yang dikeluarkan dari model penduga adalah variabel luas lahan, pupuk Urea, dan pupuk Phonska sehingga, diperoleh hasil output model penduga fungsi produksi petani responden sebagai berikut.

Tabel 1.

Estimasi Model Fungsi Produksi Padi Petani Pengguna dan Bukan Pengguna Kredit PUAP

\begin{tabular}{lcccc}
\hline Variabel & Koefisen & t-hitung & P-Value & VIF \\
\hline Konstanta & 4,979 & 17,112 & 0,000 & \\
Benih $\left(\mathrm{X}_{1}\right)$ & 0,834 & 14,983 & 0,000 & 6,260 \\
Pupuk Organik $\left(\mathrm{X}_{2}\right)$ & $-0,029$ & $-1,509$ & 0,137 & 2,703 \\
Pestisida $\left(\mathrm{X}_{3}\right)$ & $-0,030$ & $-0,561$ & 0,577 & 3,216 \\
Penggunaan Tenaga & 0,276 & 3,790 & 0,000 & 4,151 \\
Kerja $\left(\mathrm{X}_{4}\right)$ & 0,101 & 2,095 & 0,040 & 2,928 \\
Kredit PUAP $\left(D_{1}\right)$ & $\mathrm{R}^{2}(\operatorname{adj})=0,965$ & \\
\hline $\mathrm{R}^{2}=0,968$ &
\end{tabular}

Sumber : Data primer (diolah), 2017 
Berdasarkan hasil analisis pada tabel 1, maka diperoleh model persamaan fungsi produksi Cobb-Douglas dari usahatani padi petani responden sebagai berikut :

$\ln \mathrm{Y}=4,979+0,834 \ln \mathrm{X}_{1}-0,029 \ln \mathrm{X}_{2}-0,030 \ln \mathrm{X}_{3}+0,276 \ln \mathrm{X}_{4}+0,101 \ln \mathrm{D}_{1}$

Model persamaan diatas telah lulus uji asumsi klasik yang terdiri dari uji normalitas, uji heterokedastisitas, dan uji normalitas. Hasil uji F menunjukkan nilai $\mathrm{F}_{\text {hitung }}>\mathrm{F}_{\text {tabel }}(5 \%)$, berarti tolak $\mathrm{H}_{0}$ yang menyatakan bahwa bidang regresi penduga (Y) yang didapat tersebut adalah bidang regresi yang terbaik untuk menerangkan bahwa salah satu variabel independen ada yang berpengaruh nyata terhadap variabel dependen Y. Nilai $p$-value pada tabel 1 menunjukkan bahwa variabel dummy dapat berpengaruh secara nyata terhadap produksi pada selang kepercayaan $95 \%$.

\subsection{Hasil Analisis Pengaruh Program PUAP terhadap Tingkat Pendapatan}

Petani Padi yang Menggunakan PUAP, dibandingkan dengan Petani yang Tidak Menggunakan PUAP di Gapoktan Belega Mandiri

Analisis pendapatan usahatani menggunakan hasil perhitungan rata-rata dari responden dalam periode tiga bulan atau satu kali musim panen. Struktur biaya keseluruhan antara petani pengguna PUAP dan bukan pengguna PUAP dapat dilihat pada tabel 2 . 
Tabel 2.

Perbandingan Struktur Biaya Usahatani Padi Petani Pengguna dan Bukan Pengguna PUAP per Hektar per Musim Tanam

\begin{tabular}{|c|c|c|c|c|c|}
\hline \multirow[b]{2}{*}{ No } & \multirow[b]{2}{*}{ Komponen Biaya } & \multicolumn{2}{|c|}{ Pengguna PUAP } & \multicolumn{2}{|c|}{ Bukan Pengguna PUAP } \\
\hline & & $\begin{array}{l}\text { Nilai } \\
\text { (Rp/ha) }\end{array}$ & $\begin{array}{l}\text { Persentase } \\
(\%)\end{array}$ & $\begin{array}{l}\text { Nilai } \\
\text { (Rp/ha) }\end{array}$ & $\begin{array}{l}\text { Persentase } \\
(\%)\end{array}$ \\
\hline \multirow[t]{15}{*}{$\mathrm{I}$} & \multicolumn{5}{|c|}{ Biaya tunai } \\
\hline & \multicolumn{5}{|l|}{ Biaya tetap } \\
\hline & a. Iuran Subak & $250.000,00$ & 1,51 & $250.000,00$ & 1,64 \\
\hline & b. Pajak & $100.000,00$ & 0,60 & $100.000,00$ & 0,66 \\
\hline & Sub total & $350.000,00$ & 2,12 & $350.000,00$ & 2,30 \\
\hline & \multicolumn{5}{|l|}{ Biaya variabel } \\
\hline & a. Benih & $323.000,00$ & 1,95 & $318.000,00$ & 2,09 \\
\hline & b. Pupuk & $1.744 .071,06$ & 10,54 & $1.299 .551,74$ & 8,54 \\
\hline & c. Obat-obatan & $517.605,97$ & 3,13 & $636.760,22$ & 4,18 \\
\hline & $\begin{array}{l}\text { d. Tenaga Kerja } \\
\text { Luar Keluarga }\end{array}$ & $6.628 .527,00$ & 40,07 & $6.257 .832,00$ & 41,12 \\
\hline & e. Bagi hasil & $4.629 .751,14$ & 27,99 & $5.068 .778,88$ & 33,31 \\
\hline & $\begin{array}{r}\text { f. Angsuran } \\
\text { pinjaman }\end{array}$ & $371.436,83$ & 2,25 & - & - \\
\hline & g. Bunga pinjaman & $200.916,01$ & 1,21 & - & - \\
\hline & Sub total & $14.415 .308,00$ & 87,15 & $13.580 .922,84$ & 89,24 \\
\hline & Total biaya tunai & $14.765 .308,00$ & 89,26 & $13.930 .922,84$ & 91,54 \\
\hline \multirow[t]{6}{*}{ II } & \multicolumn{5}{|c|}{ Biaya diperhitungkan } \\
\hline & $\begin{array}{l}\text { Biaya tetap } \\
\text { a. Penyusutan alat } \\
\quad \text { pertanian }\end{array}$ & $298.063,27$ & 1,80 & 199.895 .71 & 1,31 \\
\hline & $\begin{array}{l}\text { Biaya variabel } \\
\text { a. Tenaga Kerja } \\
\text { Dalam Keluarga }\end{array}$ & $1.029 .629,60$ & 6,22 & $675.108,75$ & 4,44 \\
\hline & b. Upakara & $448.484,85$ & 2,71 & $413.030,30$ & 2,71 \\
\hline & $\begin{array}{l}\text { Total biaya } \\
\text { diperhitungkan }\end{array}$ & $1.776 .177,72$ & 10,74 & $1.288 .034,76$ & 8,46 \\
\hline & Total biaya & $16.541 .485,72$ & 100,00 & $15.218 .957,60$ & 100,00 \\
\hline
\end{tabular}

Sumber : Data primer (diolah), 2017

Besar biaya diperhitungkan yang dikeluarkan oleh petani pengguna PUAP per hektar per musim tanam lebih tinggi dibandingkan petani bukan pengguna PUAP dengan selisih sebesar Rp 488.142,95. Berdasarkan data pada tabel 2 dapat diketahui bahwa proporsi biaya tunai lebih besar dibandingkan biaya diperhitungkan baik pada petani pengguna PUAP maupun bukan pengguna PUAP. Hal ini menunjukkan bahwa dalam berusahatani petani sangat bergantung pada biaya tunai seperti pengadaan input. 
Petani pengguna PUAP mampu memperoleh penerimaan total dalam jumlah yang lebih besar dibandingkan petani bukan pengguna PUAP yang lahan garapannya lebih luas. Hal ini dikarenakan rata-rata produktivitas lahan petani pengguna PUAP lebih tinggi dibandingkan petani bukan pengguna PUAP dengan produktivitas lahan masing-masing sebesar $5.582,35 \mathrm{~kg} / \mathrm{ha}$ dan $5.012,05 \mathrm{~kg} / \mathrm{ha}$.

Pendapatan usahatani adalah hasil dari selisih antara penerimaan usahatani dengan biaya-biaya usahatani. Pada tabel 3 dapat dilihat bahwa pendapatan atas biaya tunai dan pendapatan atas biaya total petani pengguna PUAP lebih besar dibandingkan petani bukan pengguna PUAP.

Tabel 3.

Pendapatan Usahatani Petani Pengguna dan Bukan Pengguna PUAP per Hektar per Musim Tanam

\begin{tabular}{lcrr}
\hline \multicolumn{1}{c}{ Keterangan } & Satuan & $\begin{array}{c}\text { Petani Pengguna } \\
\text { PUAP }\end{array}$ & \multicolumn{1}{c}{$\begin{array}{c}\text { Petani Bukan } \\
\text { Pengguna PUAP }\end{array}$} \\
\hline Total Biaya Tunai (A) & $\mathrm{Rp}$ & $14.765 .308,00$ & $13.930 .922,84$ \\
Total Biaya Diperhitung (B) & $\mathrm{Rp}$ & $1.776 .177,72$ & $1.288 .034,76$ \\
Total Biaya (C = A+B) & $\mathrm{Rp}$ & $16.541 .485,72$ & $15.218 .957,60$ \\
Total Penerimaan (D) & $\mathrm{Rp}$ & $22.329 .412,51$ & $20.048 .182,53$ \\
Pendapatan atas Biaya Tunai & $\mathrm{Rp}$ & $7.564 .104,51$ & $6.117 .259,69$ \\
(D-A) & & & \\
Pendapatan atas Biaya Total & $\mathrm{Rp}$ & $5.787 .926,79$ & $4.829 .224,93$ \\
(D-C) & & 1,51 & 1,44 \\
R/C atas Biaya Tunai & & 1,35 & 1,32 \\
R/C atas Biaya Total & & & \\
\hline Surber: Data prim
\end{tabular}

Sumber : Data primer (diolah), 2017

Berdasarkan tabel 3 diketahui bahwa hasil analisis R/C usahatani padi petani pengguna PUAP dan bukan pengguna PUAP menguntungkan dan layak untuk dilaksanakan. Nilai R/C usahatani padi petani pengguna PUAP lebih besar dibandingkan dengan usahatani padi petani bukan pengguna PUAP. Hal ini menunjukkan bahwa usahatani padi petani pengguna PUAP lebih menguntungkan dibandingkan usahatani padi petani bukan pengguna PUAP.

Berdasarkan hasil uji-t statistik, nilai $p$-value $\mathrm{R} / \mathrm{C}$ atas biaya total $(0,010)$ lebih kecil dari $\alpha$ yang berarti bahwa rata-rata nilai $\mathrm{R} / \mathrm{C}$ atas biaya total antara petani pengguna dan bukan pengguna PUAP berbeda secara nyata pada taraf kepercayaan 95\% $(\alpha=0,05)$. Hal ini mengindikasikan bahwa usahatani yang dilakukan oleh petani pengguna PUAP lebih efisien dibandingkan dengan petani bukan pengguna PUAP. Berdasarkan hasil analisis pendapatan dapat diketahui bahwa program PUAP memberikan pengaruh yang positif terhadap pendapatan dan tepat untuk dilanjutkan. 


\section{Simpulan dan Saran}

\subsection{Simpulan}

Berdasarkan hasil analisis fungsi produksi, diperoleh kesimpulan bahwa program PUAP memiliki pengaruh nyata terhadap produksi padi di Gapoktan Belega Mandiri pada taraf kepercayaan 95\%. Hasil analisis perbandingan antara analisis regresi, uji-t statistik, dan rata-rata penggunaan input per hektar, program PUAP berpengaruh terhadap produksi karena petani pengguna PUAP memiliki produktivitas lahan yang lebih baik dibandingkan dengan petani bukan pengguna PUAP serta terdapat perbedaan pada rata-rata penggunaan input. Berdasarkan hasil analisis pendapatan usahatani padi, diperoleh bahwa pendapatan atas biaya tunai dan pendapatan atas biaya total petani pengguna PUAP lebih besar dibandingkan petani bukan pengguna PUAP. Hasil uji-t pada taraf kepercayaan $95 \%$ diperoleh hasil bahwa rata-rata nilai $\mathrm{R} / \mathrm{C}$ atas biaya total antara petani pengguna dan bukan pengguna PUAP berbeda secara nyata, berarti usahatani yang dilakukan oleh petani pengguna PUAP lebih efisien dibandingkan dengan petani bukan pengguna PUAP.

\subsection{Saran}

Saran yang dapat diberikan untuk petani, pemerintah, dan peneliti lainnya yaitu dana PUAP yang disalurkan kepada anggota Gapoktan diperluas lagi, sebaiknya petani anggota Gapoktan Belega Mandiri memperhatikan kembali penggunaan faktor produksi, pemerintah hendaknya melakukan pengawasan lebih lanjut untuk meminimalisir kecurangan dalam penyaluran dana PUAP, dan bagi peneliti yang akan melakukan penelitian di Gapoktan Belega Mandiri, maka perlu dilakukan penelitian lanjutan tentang "Efisiensi Penggunaan Faktor Produksi Padi".

\section{Ucapan Terimakasih}

Ucapan terimakasih ini peneliti tujukan kepada seluruh pihak yang telah membantu dalam pelaksanaan penelitian hingga karya ilmiah ini bisa dipublikasikan dalam e-jurnal.

\section{Daftar Pustaka}

BPS. 2013. Rumah Tangga Sub Sektor Pertanian di Indonesia Tahun 2013. Badan Pusat Statistik Indonesia. Bali.

BPS. 2015. Gianyar dalam Angka 2015. Badan Pusat Statistik Kabupaten Gianyar. Bali

BPTP. 2015. Laporan PUAP Kabupaten Gianyar Tahun 2015. Balai Pengkajian Teknologi Pertanian Denpasar. Bali

Daryanto Arief. 2010. Pertanian, Mengapa Masih Terabaikan?. http://www.trobos.com (diakses pada tanggal 10 Oktober 2010).

Kurniawan Robert dan Yuniarto Budi. 2016. Analisis Regresi Dasar dan Penerapannya dengan $R$. Kencana. Jakarta.

Nursyamsiah Tita. 2010. Pengaruh Program Pengembangan Usaha Agribisnis Perdesaan (PUAP) terhadap Produksi dan Pendapatan Usahatani Padi. Skripsi. Departemen Agribisnis. Fakultas Ekonomi dan Manajemen. IPB. Bogor. 
Permentan. 2015. Pedoman Pengembangan Usaha Agribisnis Perdesaan Tahun Anggaran 2015 Peraturan Menteri Pertanian Republik Indonesia. http://www.pertanian.go.id/assets/upload/doc/Permentan_06_2015_Pedoman_ PUAP_2015.pdf. (diakses pada tanggal 20 Oktober 2016).

Soekartawi. 2002. Prinsip Dasar Ekonomi Pertanian. PT Raja Grafindo Persada. Jakarta.

Soekartawi. 2005. Agribisnis Teori dan Aplikasinya. PT Rajagrafindo Persada. Jakarta.

Tenaya Narka. 2009. Bahan Kuliah Ekonometrika Program Studi Agribisnis. Denpasar. 